\title{
Degradation of Paracetamol and Norfloxacin in Aqueous Solution Using Vacuum Ultraviolet (VUV) Process
}

\author{
Thunyalux Ratpukdi
}

\begin{abstract}
The removal of pharmaceutical and personal care products (paracetamol and norfloxacin) in water by vacuum ultraviolet (VUV) process was studied. The effects of initial pharmaceutical concentrations $(1,5$ and $10 \mathrm{mg} / \mathrm{L})$, initial $\mathrm{pHs}(5$, 7 and 9), VUV powers (30, 60 and $120 \mathrm{~W}$ ) and bicarbonate concentrations (100 and $200 \mathrm{mg} / \mathrm{L}$ as $\mathrm{CaCO}_{3}$ ) were investigated. The experiments under ultraviolet (UV) condition were performed for comparative purpose. The results showed that the VUV process exhibited superior degradation performance than that by the UV process. The rates of both paracetamol and norfloxacin removals were second order reaction. Higher concentrations resulted in the decrease of pharmaceutical degradation rate. The initial $\mathrm{pH}$ had slight impact on pharmaceutical removal efficiency and the neutral $\mathrm{pH}$ showed the highest degradation efficiency. Bicarbonate obviously decreased the pharmaceutical removal .This is due to from $\mathrm{OH}^{\circ}$ scavenging and the VUV light absorption of the bicarbonate. For the effect of VUV powers, removal efficiencies increased as the increase of $V U V$ powers.
\end{abstract}

Index Terms-Paracetamol, Norfloxacin, PPCPs, Vacuum ultraviolet (VUV).

\section{INTRODUCTION}

During the past few years, there has been a concern of the occurrence of pharmaceuticals in natural water resources. The presence of these pharmaceuticals poses the threat to aquatic organisms in terms of mutagenicity as well as the unknown effect to human. Pharmaceuticals are originally from human and feedstock wastewaters and often found their ways into surface water sources [1]-[3]. This because they were not be effectively removed by biological wastewater treatment plant. To prevent the release of pharmaceuticals to natural water sources, other techniques beside biological treatment should be applied. Advanced oxidation processes (AOPs) are the promising technologies employing hydroxyl radicals $\left(\mathrm{OH}^{\circ}\right)$ to degrade the contaminants. Among AOPs, vacuum ultraviolet (VUV) process has gained a lot attention recently [4]-[6]. This because an advantage of VUV in that it generates $\mathrm{OH}^{\bullet}$ without addition of chemicals [7] (Eq.1). In

Manuscript received May 15, 2013; revised July 8, 2013. This work was supported in part by Thailand Research Fund, Office of the Higher Education Commission, and Khon Kaen University, Thailand under the New Researcher Grant (MRG5480184). This work was also conducted as a part of a research program "Control of hormones and antibiotics from aquatic and feedstock Industries" financially supported by Center of Excellence for Environmental and Hazardous Waste Management. The work was also supported by Farm Engineering and Automation Technology Research Group, Faculty of Engineering, Khon Kaen University.

Thunyalux Ratpukdi is with Department of Environmental Engineering, Faculty of Engineering, Khon Kaen University, Khon Kaen 40002, Thailand and Center of Excellence for Environmental and Hazardous Waste Management, Bangkok 10330, Thailand (e-mail: thunyalux@kku.ac.th). addition, the contaminants can be degraded by direct photolysis.

$$
\mathrm{H}_{2} \mathrm{O}+h v(<190 \mathrm{~nm}) \rightarrow \mathrm{H}^{\bullet}+\mathrm{OH}^{\bullet}
$$

This work studied the removal of model pharmaceuticals (paracetamoal and norfloxacin) in aqueous solution by low pressure VUV $(185+254 \mathrm{~nm})$ lamps. The effect of operating parameters including initial concentrations, $\mathrm{pH}$, and bicarbonate concentrations were investigated. Ultraviolet (UV, $254 \mathrm{~nm}$ ) experiments was also conducted for comparative purpose.

\section{MAterials AND METHODS}

\section{A. Water Sample}

For preparing $10,000 \mathrm{mg} / \mathrm{L}$ of paracetamol stock solution, $10 \mathrm{~g}$ of paracetamol $\left(\mathrm{C}_{8} \mathrm{H}_{9} \mathrm{NO}_{2}\right.$, Tylenol $\left.{ }^{\circledR}\right)$ was boiled with $100 \mathrm{~mL}$ of deionized water (DI) and $20 \mathrm{~mL}$ of $5 \mathrm{M} \mathrm{H}_{2} \mathrm{SO}_{4}$ for 30 min or until dissolved. The solution was filtered with 1.2 $\mu \mathrm{m}$ glass fiber filter and then made up volume to $1000 \mathrm{~mL}$. Stock solution of norfloxacin was prepared by dissolving norfloxacin $^{\circledR}\left(\mathrm{C}_{16} \mathrm{H}_{18} \mathrm{FN}_{3} \mathrm{O}_{3}\right)$ with deionized water. Specific concentrations of paracetamol norfloxacin were prepared from stock solutions. Sodium bicarbonate was used to prepare stock solution of $10,000 \mathrm{mg} / \mathrm{L}$ as $\mathrm{CaCO}_{3}$. This stock solution will be diluted with DI water for experiment studying the effect of bicarbonate.

\section{B. Experimental Setup and Procedure}

The reactor of VUV process was a 10-L glass cylinder reactor which has a diameter of $23 \mathrm{~cm}$ and a height of $33 \mathrm{~cm}$. Four VUV lamps (30W/lamp, model GPH383T5/VH/HO, Universal Light Source, Inc.) were immersed in water and placed evenly in the reactor. Mixing was provided using paddle motor at $60 \mathrm{rpm}$. UV process was setup in similar fashion like VUV process except that a UV lamp (30W/lamp, model GPH383T5/L/HO Universal Light Source, Inc.) was replaced. It is noted that the VUV lamps used in this research were the lamp that emit wavelength of 185 and $254 \mathrm{~nm}$ while UV lamps only emit the wavelength of $254 \mathrm{~nm}$. Experiments were conducted in batch mode for $60 \mathrm{~min}$. Samples were withdrawn from reactor at specific time interval of $0,2,5,10$, 20, 30, 45, and $60 \mathrm{~min}$. For VUV process, the experiments were performed by varying paracetamol and norfloxacin concentrations (1, 5, and $10 \mathrm{mg} / \mathrm{L}), \mathrm{pH}(5,7$, and 9), and VUV powers $(30,60$ and $120 \mathrm{~W})$. For UV process, only UV power of $120 \mathrm{~W}$ was used with various bicarbonate concentrations $\left(0,100\right.$, and $200 \mathrm{mg} / \mathrm{L}$ as $\left.\mathrm{CaCO}_{3}\right)$.

\section{Analyses}

Analyses of paracetamol and norfloxacin concentrations 
were performed by spectrophotometer (Pharma Spec UV-1700, SHIMADZU) at wavelength $242 \mathrm{~nm}$ and $272 \mathrm{~nm}$, respectively. Calibration curve of paracetamol and norfloxacin were developed from known concentration of standards prepared in section II.A (data not shown).

\section{RESUlt AND DISCUSSION}

\section{A. Effect of Initial Concentrations}

Degradation of paracetamol and norfloxacin at different initial concentrations is shown in Fig. 1a and Fig. 1b, respectively. From Fig. 1, the removal of both paracetamol and norfloxacin occurred rapidly during the first $10 \mathrm{~min}$ of reaction time and slower at later period. This could be explained that at the beginning of reaction time there were only parent compounds (parecetamol or norfloxacin) in the solution. Therefore, the parent compounds can react quickly with hydroxyl radicals or undergone photolysis. However at later period, the intermediates or byproducts were formed. These byproducts could compete with the parent compounds to react with hydroxyl radicals and absorb VUV. Degradation rates of paracetamol and norfloxacin were fitted with second order reaction. The second order reaction rates were $1.837,0.836,0.890 \mathrm{~L} / \mathrm{mg} . \mathrm{min}$ for $1,5,10 \mathrm{mg} / \mathrm{L}$, respectively. It is noted that at higher concentration, degradation of paracetamol and norfloxacin was lower than low concentration. This was due higher mass of contaminant while the amount of hydroxyl radicals and photon remained the same. Plus more intermediates were formed at high concentration
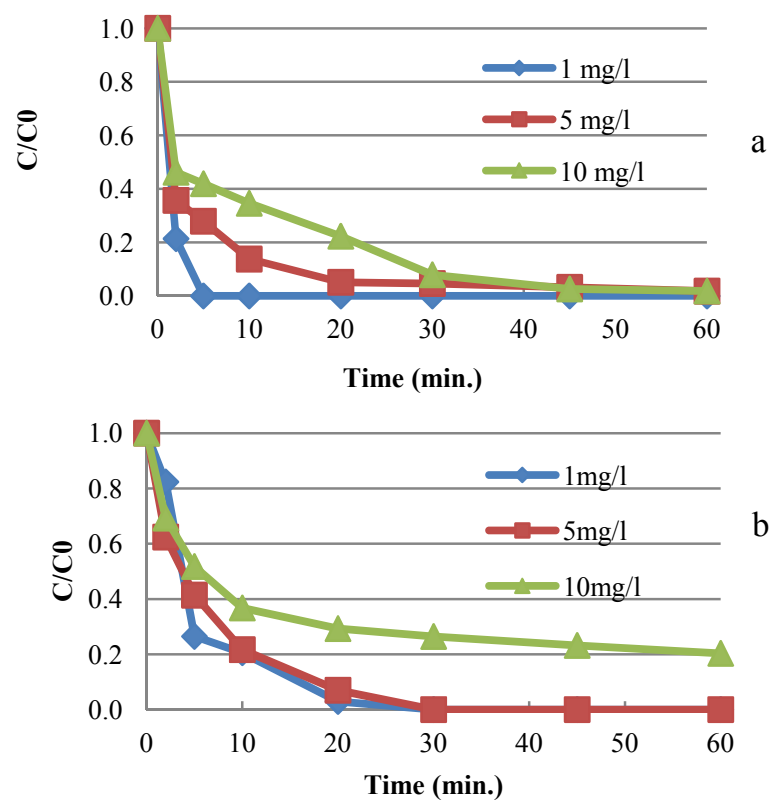

Fig. 1. Degradation of paracetamol (a) and norfloxacin (b) by VUV. Effect of initial concentrations.

\section{B. Effect of $p H$}

Fig. 2a and Fig. 2b show the effect of $\mathrm{pH}$ on degradation of paraetamol and norlfoxacin, respectively. Apparently, the optimum $\mathrm{pH}$ for degradation of paracetamol was at 7 while pH 5 and 9 exhibited the lower degradation rates (Table I). The optimum $\mathrm{pH}$ of norfloxacin degradation ranged from 7 to 9. Tasaki et al. [8] also found that the optimum $\mathrm{pH}$ was at neutral range when studying the removal methyl orange by VUV. It was described that at too low $\mathrm{pH}$, ozone generated by reaction of dissolved oxygen and VUV (Eq. 2) was stable and lead to less formation of hydroxyl radicals. However, at high $\mathrm{pH}$ hydroxyl radicals is dissociated to oxygen anion radical $\left(\mathrm{O}^{\bullet-}\right)$ which is less reactive than hydroxyl radicals (Eq.3).

$$
\begin{aligned}
& 1.5 \mathrm{O}_{2}+h v(185 \mathrm{~nm}) \rightarrow \mathrm{O}_{3} \\
& \mathrm{OH}^{\cdot} \rightarrow \mathrm{O}^{\bullet}+\mathrm{H}^{\cdot+}(p \mathrm{Ka} 11.9)
\end{aligned}
$$

TABLE I: DEGRADATION RATE OF PARACETAMOL AND NORFLOXACIN BY

\begin{tabular}{|l|c|c|c|c|c||}
\hline $\begin{array}{l}\text { Run } \\
\text { No. }\end{array}$ & $\begin{array}{l}\text { Conc. } \\
(\mathrm{mg} / \mathrm{L})\end{array}$ & $\mathrm{pH}$ & $\begin{array}{c}\text { VUV/UV } \\
\text { power (W) }\end{array}$ & $\begin{array}{l}\mathrm{HCO}_{3}^{-} \\
\mathrm{mg} / \mathrm{L} \text { as } \\
\mathrm{CaCO}\end{array}$ & $\begin{array}{c}\text { Second order rate } \\
\text { constant } \\
(\mathrm{L} / \mathrm{min}-\mathrm{mg})\end{array}$ \\
\hline \multicolumn{7}{|l||}{ Paracetamol } \\
\hline 1 & 1 & 7 & 120 & 0 & 1.837 \\
\hline 2 & 5 & 7 & 120 & 0 & 0.836 \\
\hline 3 & 10 & 7 & 120 & 0 & 0.890 \\
\hline 4 & 10 & 5 & 120 & 0 & 0.163 \\
\hline 5 & 10 & 9 & 120 & 0 & 0.866 \\
\hline 6 & 10 & 7 & 120 & 100 & 0.107 \\
\hline 7 & 10 & 7 & 120 & 200 & 0.063 \\
\hline 8 & 10 & 7 & 30 & 0 & 0.012 \\
\hline 9 & 10 & 7 & 60 & 0 & 0.028 \\
\hline 10 & 10 & 7 & $120 *$ & 0 & 0.008 \\
\hline Norfloxacin & \multicolumn{7}{|l||}{} \\
\hline 1 & 1 & 7 & 120 & 0 & 1.637 \\
\hline 2 & 5 & 7 & 120 & 0 & 0.666 \\
\hline 3 & 10 & 7 & 120 & 0 & 0.061 \\
\hline 4 & 10 & 5 & 120 & 0 & 0.030 \\
\hline 5 & 10 & 9 & 120 & 0 & 0.070 \\
\hline 6 & 10 & 7 & 120 & 100 & - \\
\hline 7 & 10 & 7 & 120 & 200 & - \\
\hline 8 & 10 & 7 & 30 & 0 & 0.031 \\
\hline 9 & 10 & 7 & 60 & 0 & 0.044 \\
\hline 10 & 10 & 7 & $120^{*}$ & 0 & 0.055 \\
\hline
\end{tabular}
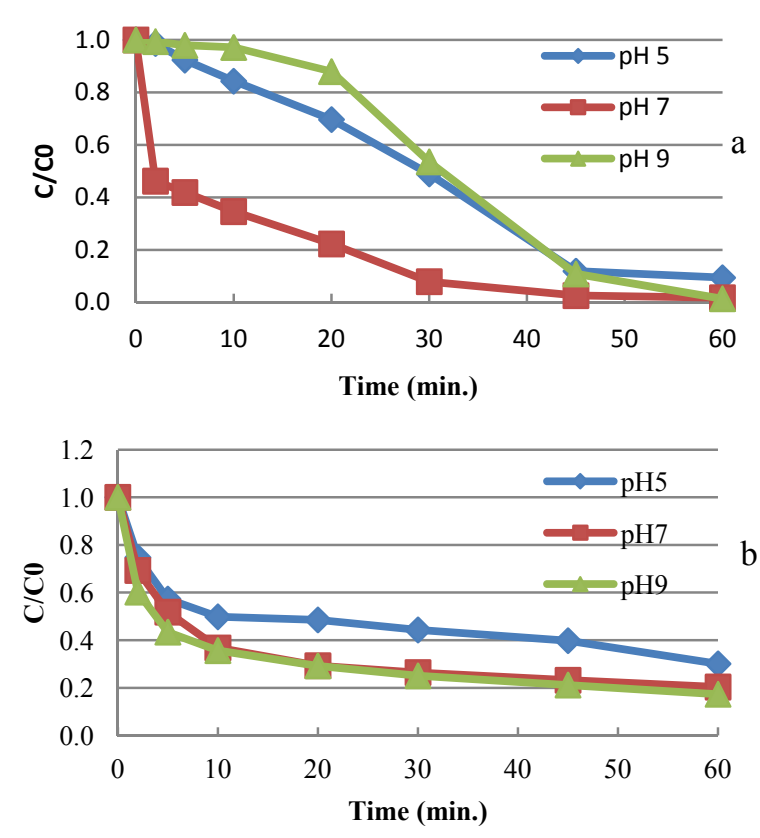

Fig. 2. Degradation of paracetamol (a) and norfloxacin (b) by VUV. Effect of $\mathrm{pH} . \mathrm{C}_{0}=10 \mathrm{mg} / \mathrm{L}$. 


\section{Effect of VUV Power and UV}

The degradation of paracetamol and norfloxacin under various VUV powers and comparison with UV is shown in Fig. 3a and Fig. 3b, respectively. Obviously, the increase of VUV power increased the of degradation rate. This was because more hydroxyl radicals generation and photolysis reaction by 185 and $254 \mathrm{~nm}$ wavelength to break down the contaminant [4]. UV performed less effective than VUV. This was due to the UV can emit only wavelength of $254 \mathrm{~nm}$ which can degrade contaminant via direct photolysis alone.

\section{Effect of Bicarbonate Concentration}

The effect of bicarbonate concentration of paracetamol and norfloxacin by VUV is described in Fig. 4a and Fig. 4b, respectively. Typically, the presence of bicarbonate could decrease the reaction rate of contaminant degradation because $\mathrm{HCO}_{3}{ }^{-}$acts as scavenger. This phenomenon was correct for paracetamol. However, for norfloxacin degradation, bicarbonate ions result in more rapid degradation. This discrepancy still needs further investigation.
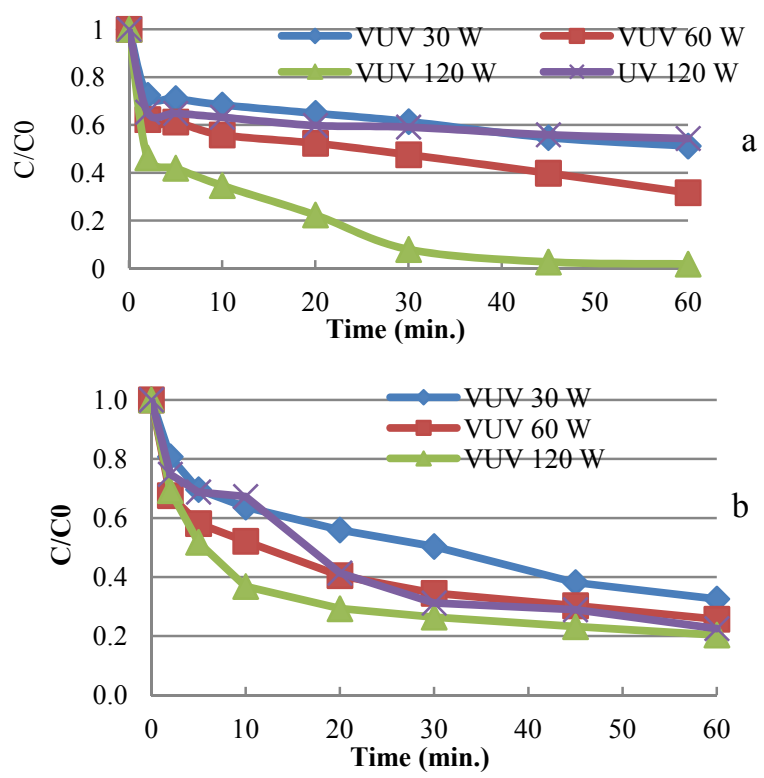

Fig. 3. Comparison of VUV and UV on degradation of paracetamol (a) and norfloxacin (b). $\mathrm{C}_{0}=10 \mathrm{mg} / \mathrm{L}$.
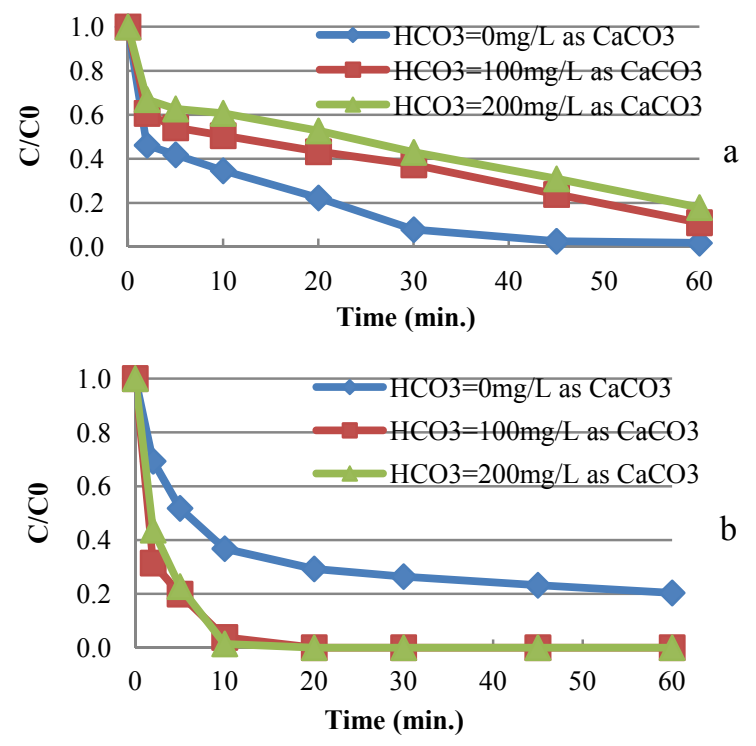

Fig. 4. Degradation of paracetamol (a) and norfloxacin (b) by VUV. Effect of bicarbonate concentration. $\mathrm{C}_{0}=10 \mathrm{mg} / \mathrm{L}$.

\section{CONCLUSION}

From this research, the increase of concentrations of paracetamol and norfloxacin reduced the degradation rate. The $\mathrm{pH}$ was found to be optimum at neutral range. The increase of VUV power caused an increase of paracetamol and norfloxacin degradation due to more hydroxyl radicals formation and more photolysis reaction. UV exhibited the lower paracetamol and norfloxacin removal efficiency than VUV. Bicarbonate tended to lower degradation efficiency. The reduction of paracetamol and norfloxacin appeared to fit second order reaction kinetic. Paracetamol had higher degradation rates than norfloxacin. This could be the chemical structure of the paracetamol that is more susceptible to oxidation and photolysis compared to norfloxacin.

\section{ACKNOWLEDGMENT}

Author thanks Pongsathorn Homwong, Panukorn Yasoongnoen and Narunat Sewiwat from Department of Environmental Engineering, Faculty of Engineering, Khon Kaen University, Thailand for their help in the experiment.

\section{REFERENCES}

[1] X. Yang, R. C. Flowers, H. S. Weinberg, and P. C. Singer, "Occurrence and removal of pharmaceuticals and personal care products (PPCPs) in an advanced wastewater reclamation plant," Water Res., vol. 45, pp. 5218-5228, 2011.

[2] M. Fram and K. Belitz, "Occurrence and concentrations of pharmaceutical compounds in groundwater used for public drinking-water supply in California," Sci. Total Environ., vol. 409, pp. 3409-3417, 2011

[3] S. García, G. Pinto, P. Encina, and R. Mata, "Consumption and occurrence of pharmaceutical and personal care products in the aquatic environment in Spain," Sci. Total Environ., vol. 444, pp. 451-465, 2013

[4] T. Ratpukdi, S. Siripattanakul, and E. Khan, "Mineralization and biodegradability enhancement of natural organic matter by ozone-VUV in comparison with ozone, VUV, ozone-UV, and UV: effects of pH and ozone dose," Water Res., vol. 44, pp. 3531-3543, 2010.

[5] R. K. Szabó, C. Megyeri, E. Illés, K. Gajda-Schrantz, P. Mazellier, and A. Dombi, "Phototransformation of ibuprofen and ketoprofen in aqueous solutions," Chemosphere, vol. 84, pp. 1658-1663, 2011

[6] L. Huang, H. Jing, Z. Cheng, and W. Dong, "Different photodegradation behavior of 4-tert-octylphenol under UV and VUV irradiation in aqueous solution," J. Photoch. Photobio. A, vol. 251, pp. 69-77, 2013

[7] T. Oppenlander, Photochemical Purification of Water and Air, Wiley-VCH: Weinheim, Germany, 2003.

[8] T. Tasaki, T. Wada, K. Fujimoto, S. Kai, K. Ohe, T. Oshima, Y. Baba, and M. Kukizaki, "Degradation of methyl orange using short-wavelength UV irradiation with oxygen microbubbles," Chemosphere, vol. 162, pp.1103-1110, 2009.

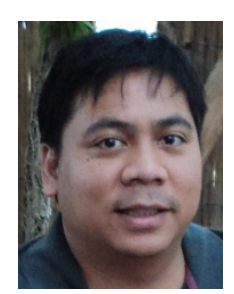

Thunyalux Ratpukdi was born in Khon Kaen, Thailand. He received Bachelor of Engineering (Environmental Engineering) from King Mongkut's University of Technology Thonburi, Thailand in 1999 and Master of Science (Environmental Management) from Chulalongkorn University, Thailand in 2002. Then, he obtained Ph.D. in Civil Engineering from North Dakota State University, USA in 2009. He started working as a university faculty at Department of Environmental Engineering, King Mongkut's University of Technology Thonburi, Thailand in 2010. He, then, moved to Department of Environmental Engineering, Khon Kaen University, Thailand in 2011.

His research field is water treatment processes and characterization. His works have been published in different international journals. 